\title{
BMJ Open Assessing the knowledge, attitudes and perceptions of tobacco-associated diseases and how it is influenced by tobacco products advertisement, promotion and sponsorship while enforcing a strong and comprehensive ban in Panama: a cross-sectional study
}

\author{
Hedley Knewjen Quintana, ${ }^{1}$ Víctor Herrera, ${ }^{1}$ Cecilio Niño, ${ }^{1}$ Beatriz Gómez, ${ }^{1}$ \\ Reina Roa ${ }^{2}$
}

To cite: Quintana HK, Herrera V, Niño C, et al. Assessing the knowledge, attitudes and perceptions of tobaccoassociated diseases and how it is influenced by tobacco products advertisement, promotion and sponsorship while enforcing a strong and comprehensive ban in Panama: a crosssectional study. BMJ Open 2019;9:e024373. doi:10.1136/ bmjopen-2018-024373

- Prepublication history and additional material for this paper are available online. To view these files, please visit the journal online (http://dx.doi. org/10.1136/bmjopen-2018024373).

Received 24 May 2018 Revised 14 March 2019 Accepted 30 April 2019

Check for updates

(c) Author(s) (or their employer(s)) 2019. Re-use permitted under CC BY-NC. No commercial re-use. See rights and permissions. Published by BMJ.

For numbered affiliations see end of article.

Correspondence to Dr Hedley Knewjen Quintana; hquintana@gorgas.gob.pa

\section{ABSTRACT}

Objectives Assessing the knowledge, attitudes and perceptions (KAP) of tobacco-associated diseases, and how it is influenced by tobacco products' advertisement, promotion and sponsorship (TAPS) while enforcing a strong and comprehensive ban.

Design The Panamanian implementation of the Global Adult Tobacco Survey: an international standardised crosssectional survey study.

Setting National Panamanian population aged between 15 years and 29 years old.

Participants There were 4796 responding participants ( $n=905830$ in the expanded sample).

Primary and secondary outcomes An index was developed using factorial analysis using TAPS and KAP variables. The primary outcomes were: (1) The national median index value. (2) The index value stratified by sex, age, occupation, income quintile and geographical areas. (3) The first and second factor loadings (FFL and SFL, respectively) for variables included in the KAP index. Results Fifteen out of the 16 variables comprising the index were variables related to KAP and one variable was related to TAPS. The top three variables according to their FFL were 'KAP that cigarette is associated to ...': (1) '... bladder cancer'. (2) '... breast cancer'. (3) '.... stomach cancer'. The top three variables according to the SFL were 'KAP that cigarette is associated to ...': (1) '... chronic bronchitis'. (2) '... myocardial infarction'. (3) '... lung cancer'. Illegal tobacco advertisement in posters was the only TAPS variable included in the index. The national KAP index value was 0.26 . Our results show that current smokers, teens, men, people with the lowest income quintile, and those living in Guna Yala Indigenous Territory (health region with the highest smoking prevalence) had a lower median value than the national median.

Conclusions Men, young adults and deprived youth had the lowest median KAP index. Illegal TAPS had no influence on the KAP of tobacco-associated diseases when a strong and comprehensive ban is enforced.
Strengths and limitations of this study

The Global Adult Tobacco Survey is an international standardised protocol to assess key tobacco control measures.

- Our results show how tobacco products' advertisement, promotion and sponsorship (TAPS) influences on knowledge, attitudes and perceptions (KAP) are hindered when a strong and comprehensive ban is enforced.

- It is not possible to assess the KAP of tobacco-associated diseases before the TAPS ban was implemented.

- TAPS in new media (mainly internet-based media) could not be assessed.

- TAPS related to electronic tobacco products could not be assessed.

\section{INTRODUCTION}

Tobacco products prematurely kill a half of their consumers and also people who are exposed to secondhand smoke. ${ }^{1}$ Panamanian authorities, in order to decrease tobacco products' consumption, have fully implemented the Framework Convention on Tobacco Control (FCTC) ${ }^{2}$ as a law in $2008 .^{3}$ In Panama, the full implementation of FCTC seems to have decreased the current tobacco consumption prevalence, from $9.4 \%$ in 2007 to $6.3 \%$ in $2013 .{ }^{4}$ A sharp decrease in myocardial infarction admissions in Panama, probably attributed to the FCTC implementation, has also been documented. ${ }^{5}$

The tobacco industry (TI) is interested in selling their products to young individuals, as earlier documented. ${ }^{6}$ TI has spent more than 
US $\$ 8$ billion dollars in tobacco advertisement, promotion and sponsorship (TAPS), as defined by the FCTC, ${ }^{2}$ in $2015 .{ }^{7}$ TAPS seems to be a key factor to induce the initiation of consumption among young people, particularly when a ban is not enforced. ${ }^{6}$ However, in Panama, there is a strong and comprehensive nationwide TAPS ban due to the full implementation of FCTC. ${ }^{3}$ Although, TAPS particularly addresses young people using new media, ${ }^{6}$ there is also a large body of evidence of tobacco products-associated diseases ${ }^{18}$ that might have permeated to young people influencing their knowledge, attitudes and perceptions (KAP) of such diseases that perhaps counter the TAPS effects that TI wants to influence the youth in order to foster initiation and to hinder quitting their products' use.

\section{OBJECTIVE}

Assessing the KAP of tobacco-associated diseases and how it is influenced by TAPS while enforcing a strong and comprehensive ban.

\section{METHODS}

\section{Study design, setting and participants}

The Global Adult Tobacco Survey (GATS) is a national representative household survey performed in some low-income and middle-income countries. ${ }^{4}$ GATS enables countries to collect data on adult tobacco use and key tobacco control measures. ${ }^{5}$ GATS-Pan is described in full in the WHO's Panamanian GATS full report. ${ }^{9}$ GATS-Pan includes additional items in order to evaluate other key tobacco control measures, particularly those that assess TAPS ban enforcement, ${ }^{9}$ as required by the FCTC local implementation. ${ }^{3}$ GATS-Pan relied on a representative nationwide sample, selected randomly, which considered 959 primary sampling units that were distributed in 14 health regions of the country, and a sampling size of 19603 households. The total response rate was $88.4 \%$, which resulted in 16962 complete individual interviews with respondents $(\mathrm{n}=2691551){ }^{9}$

\section{Data collection}

The GATS protocol standardised questionnaire was translated to Spanish which is the national language. The questionnaire was applied between 16 January and 21 May 2013. An electronic questionnaire was employed to collect and process information through the use of wireless electronic devices.

\section{TAPS variables}

The following questions assessed exposure to TAPS:

1. 'Have you noticed any images, announcements, signboards or advertisements encouraging smoking in any of the following within the last 30 days ...:

- ... on shops where tobacco products are sold?' (GATS question code: G04a)

- ... on television?' (GATS question code: G04b)

- ... on the radio?' (GATS question code: G04c)

- ... on billboards?' (GATS question code: G04d)
- ... on posters?' (GATS question code: G04e)

- ... in newspapers or magazines?' (GATS question code: G04f)

- ... in cinemas?' (GATS question code: G04g)

- ... on the Internet?' (GATS question code: G04h)

- ... on mass transportation vehicles?' (GATS question code: G04i)

- ... on public walls?' (GATS question code: G04j)

- ... on any other place?' (GATS question code: G04k)

2. 'Have you noticed any sports or sports events that are associated with cigarette brands or firms within the last 30 days?' (GATS question code: G05)

3. 'Have you encountered any of the following situations to encourage smoking within the last 30 days ...

- ... free samples of cigarettes?' (GATS question code: G06a)

- ... discounted cigarettes?' (GATS question code: G06b)

- ... coupons for discounted cigarettes?' (GATS question code: G06c)

- ... cigarettes bundled with gifts?' (GATS question code: G06d)

- ... clothing having a cigarette brand or logo on it?' (GATS question code: G06e)

- ... body paint having a cigarette brand or logo on it?' (GATS question code: G06f)

Each participant who answered 'yes' to a TAPS query was considered exposed to that particular item.

\section{KAP variables}

The following queries assessed the KAP of tobacco-induced diseases:

1. 'Based on what you know or believe, does smoking tobacco cause ....

- ... stroke?' (GATS question code: H02a)

- ... myocardial infarction?' (GATS question code: $\mathrm{H} 02 \mathrm{~b})$

- ... lung cancer?' (GATS question code: H02c)

- ... emphysema?' (GATS question code: H02d)

- ... chronic bronchitis?' (GATS question code: H02e)

- ...bladder cancer?' (GATS question code: H02f)

- ...breast cancer?' (GATS question code: H02fg)

- ...stomach cancer?' (GATS question code: H02h)

- ... abortion and premature birth?' (GATS question code: $\mathrm{H} 02 \mathrm{i}$ )

- ...premature wrinkles?' (GATS question code: $\mathrm{H} 02 \mathrm{j}$ )

- ...tooth cavities ?' (GATS question code: H02k)

- ...erectile dysfunction?' (GATS question code: H02l)

- ... hair loss?' (GATS question code: H02m)

- ... loss of calcium in the bone (osteoporosis)?' (GATS question code: H02n)

2. 'Based on what you know or believe, does using smokeless tobacco cause serious illness?' (GATS question code: $\mathrm{H} 03$ ) 
3. 'Do you believe cigarettes are addictive?' (GATS question code: H02_3)

Each participant who answered 'yes' to a given KAP variable of a tobacco-associated disease query was considered that has KAP to the respective disease.

\section{Other variables}

Respondents who answered 'daily' or 'less than daily' to the questions 'Do you currently (smoke tobacco/use smokeless tobacco) on a daily basis, less than daily, or not at all?' were considered 'current smokers' or 'current smokeless tobacco user', respectively.

The sociodemographic and socioeconomic variables used in our analyses were sex, age in three categories (late teens: $15-19$ years, early young adults: $20-24$ years and late young adults: 25-29 years), highest level of education (did not graduate or no schooling, graduated from primary school, graduated from secondary school or graduated from university), employment in three categories (student, employed/house making and unemployed). Five early young adults and two late young adults were retired and they were excluded from the analyses. Monthly income was classifed according to its quintile distribution in the GATS population.

Panama was divided into 14 health regions when GATS-Pan was implemented. Eight of them correspond to Panamanian provinces (Bocas Del Toro, Coclé, Colón, Chiriquí, Darién, Herrera, Los Santos and Veraguas) and two of them to indigenous territories (Ngäbe-Buglé and Guna Yala). The province of Panama is divided into four health regions: Panama Este, Panama Metro, Panama Oeste and San Miguelito.

\section{Statistical analyses}

The sample size in GATS-Pan was calculated using the proportion of 15 years old and older, considering a confidence level of $95 \%$, a design effect of 1.5 , a maximum expected relative error of $3.9 \%$, and a maximum expected no-response rate of $10 \%$, a national sample of 17,570 particular households was obtained as described in the GATS online documentation. ${ }^{9}$ For this study, we selected participants aged 29 years or younger.

We described the proportion of current tobacco use, in the expanded population, and stratified by age categories, sex and geographical areas.

We assessed the national median value of the KAP index. We compared the national median value with the median stratified value of the index by sex, age categories, geographical areas, occupation and individual income. We drew a choropleth map to show the index median value according to health regions.

A KAP index was developed from factorial analysis by principal component with tetrachoric correlation matrix using TAPS and KAPS variables with varimax rotation in two phases. Variables with loadings greater than 0.1 in the first factor of the first analysis phase were kept in the next phase. The loadings of the variables in the second phase for the first factor loading (FFL) and second factor loading (SFL) and the variable distributions are presented by age group, sex and geographical areas. Missing data are excluded from the analyses.

We also present TAPS variables not included in the index as supplementary analyses stratified by age group, sex and geographical areas.

All analyses were run under R V.3.4.3. The 'survey' package V.3.23.1 was used for describing the population taking into account sampling weights. The 'psych' package V.1.7.8 was used for calculating the factor analyses taking into account sampling weights.

\section{Patient and public involvement}

GATS-Pan development was a collaboration among international and Panamanian governmental institutions, as it is stated in the report of this survey. ${ }^{9}$

\section{RESULTS}

\section{Participants and population under study}

There were 4796 selected participants $(n=905830$ in the expanded sample; $34 \%$ of the expanded population). The selected population was distributed as follows: $38 \%$ late teens, $32 \%$ early young adults and $30 \%$ late young adults (table 1). Regarding education, late young individuals tended to have attained higher education than younger peers. However, the proportion of young individuals without formal education increased with age (table 1). Youth living in urban areas earn a higher income than peers who lived in rural and indigenous areas (table 1). Current tobacco smoking was $5.5 \%$ in the selected population, $2.5 \%$ among late teens, $5.3 \%$ among early young adults and $9.5 \%$ in late young adults. The smoking prevalence was $8.1 \%$ in male young adults and $2.8 \%$ in female young adults. The prevalence of current smoking in urban areas was $6.6 \%$, in rural areas $2.6 \%$ and in indigenous areas $6.3 \%$. The prevalence of current use of smokeless tobacco users was $0.3 \%$ in teens, $0.6 \%$ in early young adults and $0.5 \%$ in late young adults.

\section{KAP index}

As shown in figure 1, 5 out of 14 health regions have a median KAP value below the national median: Panama Oeste (0.207), Los Santos (0.170), Panama Metro (0.155), Guna Yala Indigenous Territory (0.066) and Panama Este (0).

The median KAP values according to other variables are shown in figure 2 . The national median value for the KAP index was 0.26. Current smokers had a lower median KAP index value than the national median $(0.17)$. The KAP index median value in men was slightly lower than the median value in women (men: 0.25 ; women: 0.28 ). Teens had a lower KAP index than the national median (0.15). People living in rural geographical areas had a KAP median index value lower than the national median (0.14). People in the lowest quintile of the GATS income level had a KAP index below the national median $(-0.04)$, 


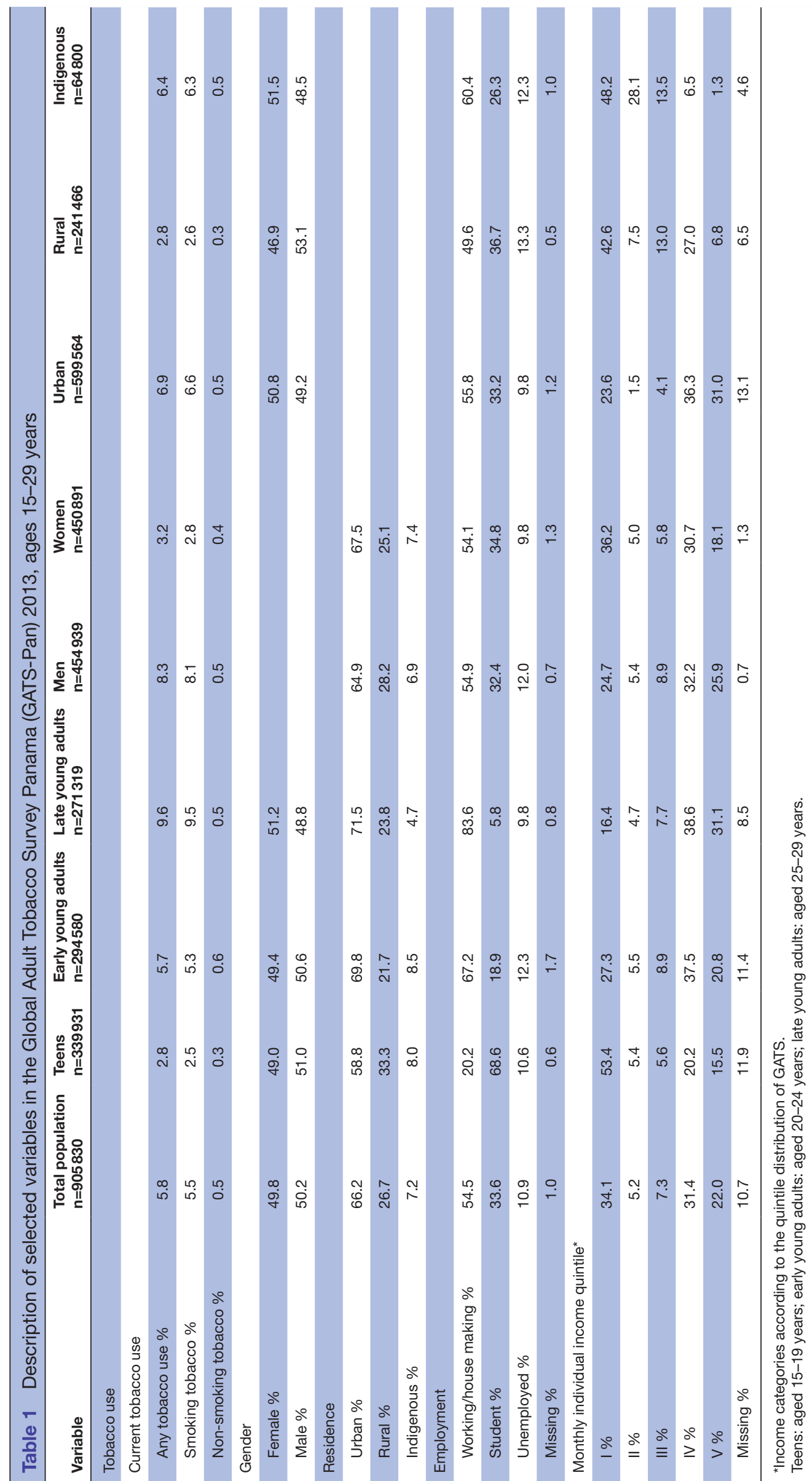




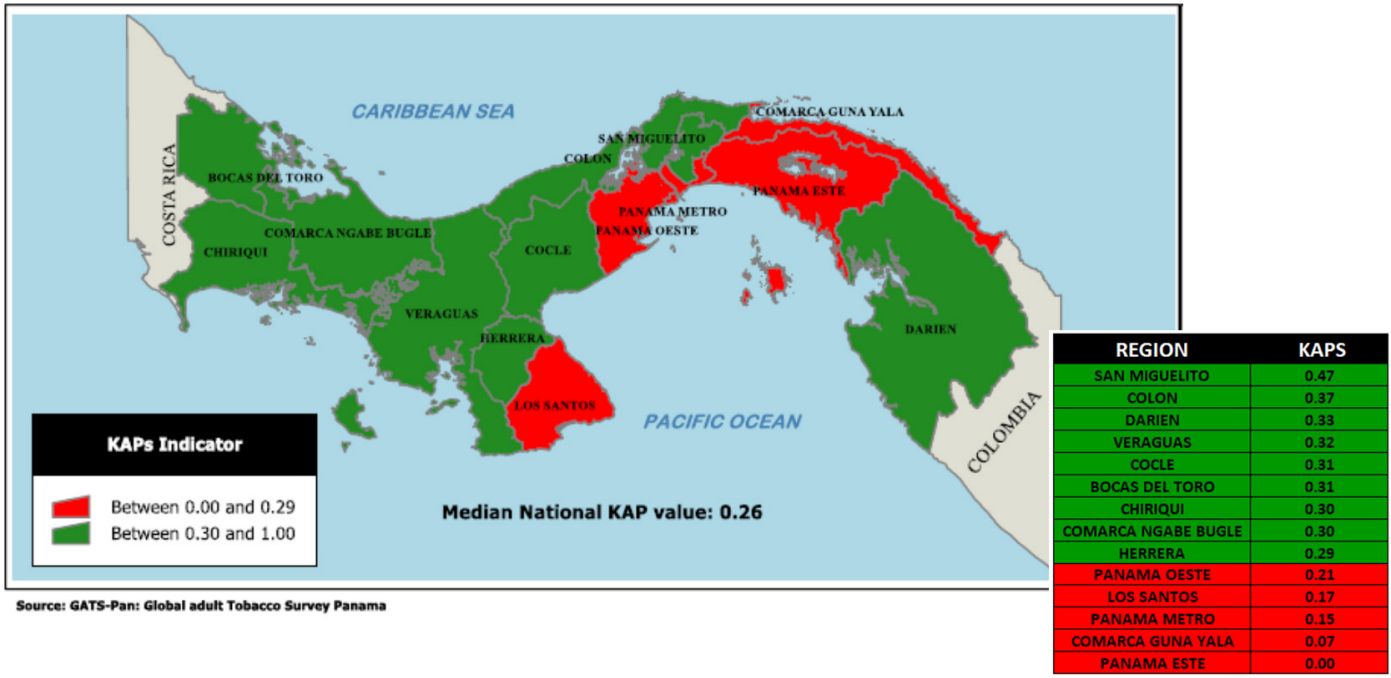

Figure 1 Knowledge, attitudes and perceptions (KAP) of the tobacco-associated diseased index according to health region in Panama among persons aged 15-29 years in the Global Adult Tobacco Survey Panama (GATS-Pan) 2013.

while people in other quintiles had index values above the national median.

The variables included in the KAP index are shown in table 2 sorted by the FFL. The final KAP index contains 16 variables. The Kaiser-Meyer-Olkin measure of the sampling adequacy value of the final KAP index was 0.9 . The first two factors account for $72 \%$ of the latent variable. Fifteen out of 16 variables composing the index


Figure 2 Knowledge, attitudes and perceptions (KAP) of the tobacco-associated diseased index according to smoking status, age category, income quintile, socioeconomic activity and geographical region among persons aged 15-29 years in the Global Adult Tobacco Survey Panama (GATS-Pan) 2013.

are related to KAP. The questions concerned with dangers of tobacco product use included in the index were the 'KAP that cigarette is associated to...': (1) ' $\ldots$ bladder cancer' (FFL: 0.71). (2) '... breast cancer' (FFL: 0.67).(3) '... stomach cancer' (FFL: 0.63). (4) ' $\ldots$ hair loss' (FFL: $0.62)$. (5) '... loss of calcium in bone (osteoporosis)'. (6) ‘... sexual impotence' (FFL: 0.51). (7) '... wrinkles' (FFL: 0.35). (8) ‘... myocardial infarction’ (FFL: 0.33). (9) ‘...
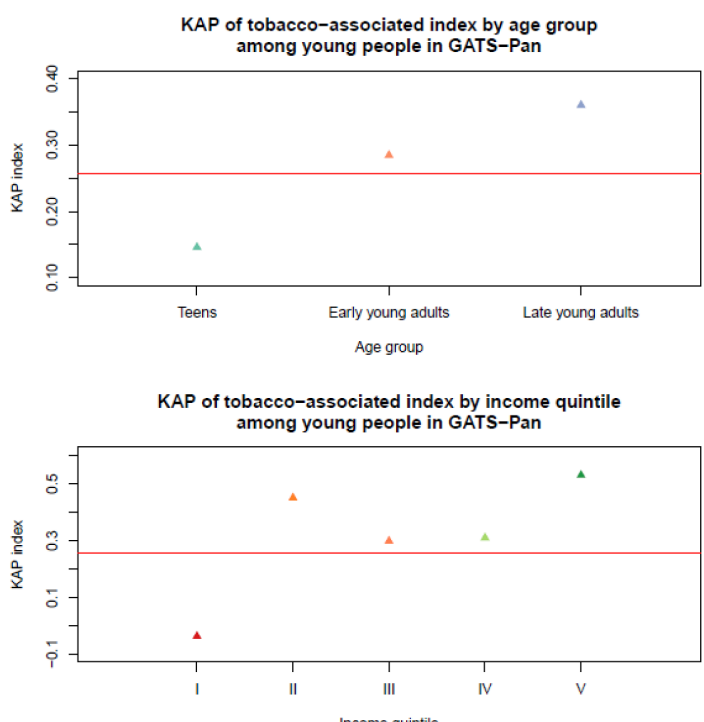


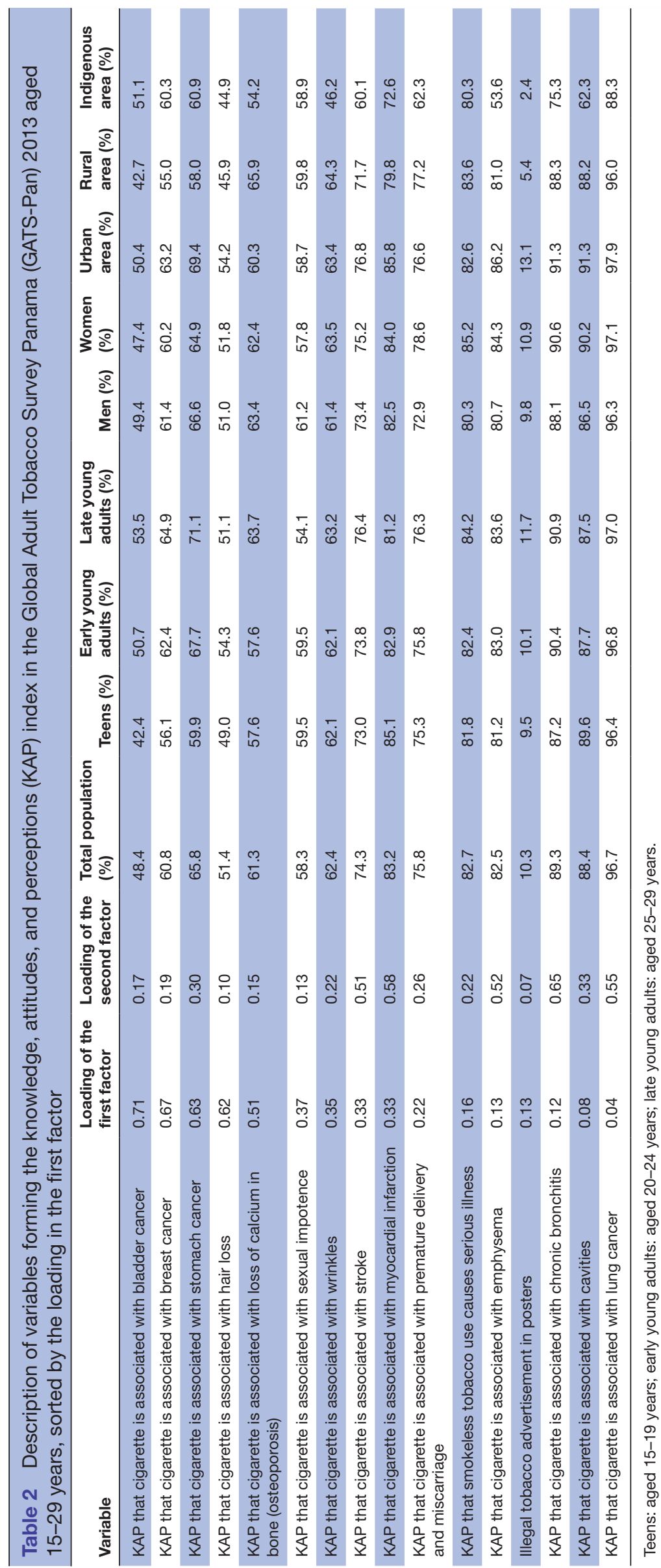


stroke' (FFL: 0.33). (10) '... miscarriages' (FFL: 0.22). (11) 'KAP that smokeless tobacco use is related to serious illness' (FFL: 0.16). (12) '... emphysema' (FFL: 0.13). (13) '... chronic bronchitis' (FFL: 0.12). (14) '... cavities' (FFL: 0.08). (15) '... lung cancer' (FFL: 0.04). As shown in table 2, more than a half of the population identifies each of the aforementioned diseases as associated with tobacco products use, except for bladder cancer (48.4\% of the population). The KAP index values were missing for $2.75 \%$ of the young population.

The top five variables with the highest loadings in the SFL were the 'KAP that cigarette is associated to ...': (1) '... chronic bronchitis' (SFL: 0.65). (2) '... myocardial infarction' (SFL: 0.58). (3) '... lung cancer' (SFL: 0.55). (4) '... emphysema' (SFL: 0.52). (5) '... stroke' (SFL: 0.58 ). More than $85 \%$ of the young persons in the population correctly identify each of these diseases as associated with cigarette smoking.

As shown in table 2, illegal tobacco advertisement in posters was the only representative of TAPS in the KAP index. Illegal tobacco advertisement in posters was seen by $10.3 \%$ of the population. The illegal tobacco advertisement in posters variable had low loadings in both the first and the second factors (FFL: 0.13; SFL: 0.07). Other TAPS variables not included in the index are shown in online supplementary table 1 .

\section{DISCUSSION}

Tobacco use leads to severe diseases, earlier documented in detail by the United Stated Center for Disease Control and Prevention (US-CDC) General Surgeon report in 2014. ${ }^{8}$ Among these diseases, the index we developed was mainly driven by the KAP awareness of the following smoking-associated diseases: bladder cancer, breast cancer, stomach cancer, hair loss, osteoporosis, sexual impotence, wrinkles, myocardial infarction, stroke, miscarriages, emphysema, chronic bronchitis, cavities and lung cancer. Our results synthesise the KAP of tobacco-associated diseases among young Panamanians. The GATS atlas solely compares the KAP of the following tobacco-associated health problems: myocardial infarction, stroke and lung cancer. ${ }^{10}$ The KAP that smoking is associated with myocardial infarction and stroke were quite similar in the American continent, but they were lower in China, the Russian Federation and South-East Asia. ${ }^{10}$ Lung cancer is identified by each of the different GATS as a health problem associated with smoking all around the world. ${ }^{11}$ Although, according to our results, the awareness that lung cancer is associated with tobacco use by the Panamanian youth had the lowest impact in the first factor of KAP of tobacco-associated diseases, such awareness had one of the highest loadings in the second factor of the index. The awareness of other tobacco health-related problems are rarely assessed in the literature. For instance, an early study assessed whether people are aware that smoking causes diseases, but the diseases were equally weighted. ${ }^{11}$
A variable assessing the KAP of smokeless tobacco-associated diseases was also identified in the KAP index with a small loading in the first factor and moderate in the second one. Panama has a very low prevalence of smokeless tobacco use $(0.5 \%)$. The proportion of young people with KAP of smokeless tobacco-associated diseases was identified to be high in Panama (82.7\%). Similar results regarding the awareness of smokeless tobacco are also observed in other countries, except China, Poland and Nigeria with proportions of persons aware of smokeless tobacco-associated diseases below $80 \% .^{10}$

Our findings showed that current tobacco users had a lower median KAP value than tobacco never-users. Our results are congruent with a Chinese study where an index of three KAPs that smoking is associated with myocardial infarction, stroke and lung cancer is lower among smokers than non-smokers. ${ }^{11}$ These results might be an indication that the current smokers might lack the KAP of tobacco-associated diseases which in turn, might facilitate initiation of tobacco use as earlier documented. ${ }^{12}$

Teens had the lowest KAP value. It is likely that they require more exposure to information regarding the dangers of tobacco products than older groups.

Young men have a lower KAP median index value than the national median value. Regarding this finding, Panamanian men are more likely to use tobacco products than women. ${ }^{91314}$ This finding perhaps might be related to the risk-taking behaviour of the male gender that has been observed in relation to smoking, ${ }^{15}$ and other addictions. ${ }^{16}$

According to our data, the rural area had a KAP index median value below the national KAP median index value, but the urban and the indigenous areas did not. In connection to this finding an earlier report states that smokers who initiate at younger than 16 years of age are more likely to live in the rural geographical areas than the indigenous or the urban areas. ${ }^{14}$

Regarding individual income categories, the lowest quintile category was the only one that had their median KAP index below the national median KAP value. Unemployed young individuals and students also had KAP median index values below the national median. In Panama, as part of the FCTC implementation, we documented that there are elevated taxes for tobacco products, that protected these vulnerable groups. ${ }^{17} 18 \mathrm{In}$ addition to these fiscal policies, these vulnerable populations might benefit if they are educated further about tobacco-associated diseases.

When assessing the indigenous territories, the NgäbeBuglé Indigenous Territory had a median KAP index value above the national median, but the Guna Yala Indigenous territory did not. Ngäbe-Buglé has a lower prevalence of smoking than the Guna Yala indigenous territory. As far as we know, there are few studies describing the KAP of tobacco-associated dangers and the prevalence of smoking among other Latin-American indigenous populations. A Canadian study showed that the general population and the aborigines had a similar level of awareness regarding smoking as a risk factor of chronic pulmonary obstructive disease and lung cancer. ${ }^{18}$ 




Figure 3 Sorted prevalence of current smokers among late teens aged 15-24 years (2009-2014), according to the National Adult Tobacco Survey in USA (2015) and by the Global Adult Tobacco Survey elsewhere (2009-2015).

Panama Metro, Panama Este, and Los Santos are non-indigenous territories which had the lowest KAP value. Los Santos and Panama Este had thehighest proportion of rural population having the lowest KAP index value among the geographical regions might explain why these health regions have the lowest KAP index values. Panama Metro, Panama Este, Los Santos and Panama Oeste health regions represent $71 \%$ of the urban population and they had KAP index values below the national median value, despite that urban region have an index value higher than the national value. On the other hand, the San Miguelito health region, a very densely populated area and representing $10 \%$ of the urban population had the highest KAP value among the young Panamanians. A more detailed analysis of KAP index value in health regions in the urban area might be a relevant topic for further research.

Compared with other GATS, GATS-Pan had the lowest prevalence of tobacco smoking in the Americas and the bottom fifth position around the world for the age group under study (figure 3). During the GATS-Pan study period, there was strong and comprehensive enforcement of the TAPS ban in Panama in selling points, magazines, newspapers, TV and radio. According to the GATS atlas it seems to be similar to other Latin-American countries. ${ }^{10}$ Our results show that 1 out of 10 young persons had been exposed to this form of advertisement, perhaps due to the TAPS ban. The loadings of illegal tobacco advertisement in in posters in both of these factors identified were very low: such finding whindicates that such variables had a very small effect on the KAP of tobacco-associated.

We recently recorded the TAPS ban enforcement last year in traditional media and selling points. ${ }^{19}$ Last year there was a strong enforcement of TAPS ban at selling points. ${ }^{20}$ We also documented, in a recent report that the ban was enforced in the top-watched movies, and in the top-selling video games last year. ${ }^{19}$ However, TAPS was unfortunately observed in internet search engines, social media and in the WhatsApp instant messaging platform where the ban was harder to enforce, due to the nature of these new media. ${ }^{19}$ A limitation of this study is that these new aforementioned media were not assessed during the GATS-Pan implementation. Another limitation of this study is the introduction of novel tobacco products, such as the electronic cigarette, and very low nicotine cigarettes that were also not available during the GATS-Pan study period in order to assess their KAP. However, selling such new tobacco products is currently prohibited in Panama.

Although, there are previous studies documenting the impact of a TAPS ban on the public health, ${ }^{21-23}$ there are no previous studies, as far as we know, that linked the role of TAPS with the KAP of the tobacco-associated diseases that the literature has described ${ }^{8}$ while enforcing a strong and comprehensive ban.

\section{CONCLUSIONS}

There was an increased KAP of tobacco-associated diseases among Panamanian young people. The median KAP index value of tobacco-associated diseases was found to be lower than the national median in vulnerable young people: current smokers; men; teens; young persons with low income; students; young people who are unemployed but not students; and young individuals living in Guna Yala Indigenous territory, Los Santos, Panama Metro, Panama Oeste and Panama Este.

Our findings support the fact that illegal TAPS had no influence on the KAP of tobacco-associated diseases when a strong and comprehensive ban is enforced. 
Author affiliations

${ }^{1}$ Instituto Conmemorativo Gorgas de Estudios de la Salud, Panama, Panama, Panama

${ }^{2}$ Planning Directorate, Ministerio de Salud Panama, Panama City, Panama

Acknowledgements The authors thank Dr Karin Leander (Institute of Environmental Medicine, Karolinska Institute) for English language editing of this manuscript.

Collaborators Karin Leander: English language editing.

Contributors HKQ: initial manuscript writing and literature research. RR, VH, CN, BG: GATS-Pan implementation (data collection). HKQ, VH: statistical analyses. HKQ, VH, CN BG, RR: critical review of the final submitted manuscript.

Funding The data collection was financed by public funds provided by the Panamanian Economics and Finance Ministry (PEFM). The funding source had no role in the data collection, data analysis, interpretation of data, or writing of the report. The funding source required a sampling scheme that includes a rural area, an urban area and an indigenous area. US-CDC validated the sampling scheme requested by the funding source. This information is also described in the WHO Panamanian GATS full report. ${ }^{9}$ The manuscript writing was financed with public funds provided by the Panamanian Ministry of Economics and Finance to both Gorgas Memorial Institute for Health Studies, and the Panamanian Ministry of Health. Some of these public funds came from the $100 \%$ Selective Tax on the Consumption of Cigarettes and other Tobacco Products. This tax discourages the use of tobacco products as earlier documented. ${ }^{17}$ But, the funds coming from this tax are also used in activities to improve the primary and secondary prevention of tobacco-associated diseases, such as this manuscript. HKQ is a tier 1 Researcher member of the National Research System (SNI, Spanish acronym): he receives additional public funds provided by the National Research and Technology Secretary (SENACYT, Spanish acronym).

Disclaimer The depiction ofboundaries on the map(s) in this article do not imply the expression of anyopinion whatsoever on the part of BMJ (or any member of its group) concerningthe legal status of any country, territory, jurisdiction or area or of itsauthorities. The map(s) are provided without any warranty of any kind, eitherexpress or implied.

\section{Competing interests None declared.}

Patient consent for publication Obtained.

Ethics approval On first contact with a household, the interviewer explained the objectives of GATS Panama and indicated that the study was voluntary, confidential and anonymous. The confidentiality of information and the anonymity of interviewees were in fact maintained throughout the study, as the data collection instrument did not allow the identification of any names, even though they were recorded. Importantly, neither names nor personal identification numbers were registered, thereby preventing breaches of confidentiality. Interviewers requested verbal consent from a household member to obtain information on the home and a list of the residents living there. In addition, as an integral part of the survey, an electronically registered consent was obtained from all interviewees. For minors aged 15-17 years, consents from parents or guardians and approvals on behalf of these minors were designed and available on paper as well as electronically. The study was approved by the National Commission on the Bioethics of Research in Panama.

Provenance and peer review Not commissioned; externally peer reviewed.

Data sharing statement The anonymised Pan-GATS raw data are publicly available at the Global Tobacco Surveillance System Data (GTSSData), curated by the US-CDC in the following link: https://nccd.cdc.gov/GTSSDataSurveyResources/ Ancillary/DataReports.aspx?CAID=2.

Open access This is an open access article distributed in accordance with the Creative Commons Attribution Non Commercial (CC BY-NC 4.0) license, which permits others to distribute, remix, adapt, build upon this work non-commercially, and license their derivative works on different terms, provided the original work is properly cited, appropriate credit is given, any changes made indicated, and the use is non-commercial. See: http://creativecommons.org/licenses/by-nc/4.0/.

\section{REFERENCES}

1. World Health Organization. Tobacco fact sheet. 2017. http://www. who.int/mediacentre/factsheets/fs339/en/ [Accessed 24 Apr 2018].
2. World Health Organization. WHO Framework Convention on Tobacco Control. 2005;1:270-1. http://www.who.int/tobacco/framework/ WHO_FCTC_english.pdf [Accessed 24 Apr 2018].

3. Asamblea Nacional. Ley 13 que Adopta Medidas Para El Control Del Tabaco Y Sus Efectos Nocivos En La Salud. 2008. In Spanish language. https://www.gacetaoficial.gob.pa/pdfTemp/25966/8638. pdf [Accessed 24 Apr 2018)

4. World Health Organization. Global Adult Tobacco Survey (GATS). http://www.who.int/tobacco/surveillance/survey/gats/en/ [Accessed 24 Apr 2018].

5. Jan C, Lee M, Roa R, et al. The association of tobacco control policies and the risk of acute myocardial infarction using hospital admissions data. PLoS One 2014;9:e88784.

6. CDC. Chapter 5 The Tobacco Industry' s Influences on the Use of Tobacco Among Youth. Surgeon General's Report 2012:483-628. https://www.ncbi.nlm.nih.gov/books/NBK99238/\#top [Accessed 24 Apr 2018].

7. Federal Trade Commission. Cigarette Report for 2015. https://www. ftc.gov/system/files/documents/reports/federal-trade-commissioncigarette-report-2015-federal-trade-commission-smokelesstobacco-report/2015_cigarette_report.pdf [Accessed Apr 2018].

8. United States Department of Health and Human Services. The Health Consequences of Smoking - 50 Years of Progress A Report of the Surgeon General. A Report of the Surgeon General. 2014:1081. https://www.ncbi.nlm.nih.gov/pubmed/24455788 [Accessed Apr 2018].

9. Pan American Health Organization, WHO, Health Ministry of Panama. Global Adult Tobacco Survey: Panama, 2013:160. http://www.who. int/tobacco/surveillance/survey/gats/pan_report2013.pdf?ua=1 [Accessed 24 Apr 2018].

10. Asma S, Mackay J, Yang Song S, et al. The GATS Atlas. 2015. http:// gatsatlas.org [Accessed 24 Apr 2018].

11. Cheng HG, McBride O, Phillips MR. Relationship between knowledge about the harms of smoking and smoking status in the 2010 Global Adult Tobacco China Survey. Tob Control 2015;24:54-61.

12. Prabandari YS, Dewi A. How do Indonesian youth perceive cigarette advertising? A cross-sectional study among Indonesian high school students. Glob Health Action 2016;9:30914.

13. Roa R. Los Impuesto al Tabaco: La Experiencia Panameña. In Spanish language. http://apps.who.int/fctc/implementation/ database/sites/implementation/files/documents/reports/Impuesto [Accessed 24 Apr 2018].

14. Ministerio de salud de Panama ICG. ENSCAVI, capítulos 1 y 2. 2007. http://www.gorgas.gob.pa/enscavi [Accessed 24 Apr 2018]

15. Salgado MV, Pérez-Stable EJ, Primack BA, et al. Association of media literacy with cigarette smoking among youth in Jujuy, Argentina. Nicotine Tob Res 2012;14:516-21.

16. Ritter A, Cole MJ. Men's issues: gender role conflict and substance abuse. Drug Alcohol Rev 1992;11:163-7.

17. Víctor Hugo HB, Moreno Velásquez I, Beatriz G, et al. Impacto del incremento del impuesto a los productos de tabaco sobre la recaudación y los precios en Panamá. Value Health Reg Issues 2017;14:57-63.

18. Walker SL, Saltman DL, Colucci R, et al. Awareness of risk factors among persons at risk for lung cancer, chronic obstructive pulmonary disease and sleep apnea: a Canadian population-based study. Can Respir J 2010;17:287-94.

19. Ministerio de Salud de Panamá, Instituto Conmemorativo Gorgas. Investigación: Evaluación del cumplimiento de la prohibición de la publicidad, promoción y patrocinio de productos del tabaco en puntos de venta, medios de comunicación, internet, redes sociales, plataformas móviles de mensajería, videojuegos y empaquetado/ etiquetado. In Spanish language. http://www.gorgas.gob.pa/ SitioWebTabaco/documentos/Informe_PPPPT.pdf [Accessed $24 \mathrm{Apr}$ 2018].

20. Herrera Ballesteros VH, Quintana HK, Niño C, et al. Tobacco Advertisement Promotion and Sponsorship Ban Enforcement Index in Sales Points in Panama. Tob Induc Dis 2017. Forthcoming.

21. Sargent JD, Demidenko E, Malenka DJ, et al. Smoking restrictions and hospitalization for acute coronary events in Germany. Clin Res Cardiol 2012;101:227-35.

22. Zablocki RW, Edland SD, Myers MG, et al. Smoking ban policies and their influence on smoking behaviors among current California smokers: a population-based study. Prev Med 2014;59:73-8.

23. Cronin EM, Kearney PM, Kearney PP, et al. Coronary Heart Attack Ireland Registry Working $\mathrm{G}$. Impact of a national smoking ban on hospital admission for acute coronary syndromes: a longitudinal study. Clin Cardiol 2012;35:205-9. 